\title{
Measurement of an individual entrepreneur's social capital: a multidimensional model
}

\author{
Mariel Fornoni \& Iván Arribas \& José E. Vila
}

\begin{abstract}
The aim of this paper is twofold. First of all, we participate in the open discussion on the nature of social capital and we show that the one-dimensional approach is not enough to capture the complex nature of social capital. Second, we present, implement and validate a specific three-dimensional measurement tool that can be used to analyze the role of social capital in further entrepreneurship research. The measurement tool is implemented through a Structural Equation Model, which is estimated and validated from a database including information from 282 Argentinean entrepreneurs who answered a questionnaire specifically designed for this research. Our measurement model considers the dimensions proposed by Koka and Prescott (Strategic Management Journal, 23:795-816, 2002), i.e. relational, resources and structural.
\end{abstract}

Keywords Entrepreneur. Social capital · Measurement model $\cdot$ Structural equation model

\footnotetext{
M. Fornoni

Department of Management, National University of Mar del Plata, Avda. 25 de Mayo, 2855 Mar del Plata, Argentina

e-mail: marielfornoni@yahoo.com.ar

I. Arribas $(\bowtie) \cdot$ J. E. Vila

Department of Economic Analysis, ERI-CES, University of Valencia, Avda. dels Tarongers s/n, Edificio Departamental Oriental, 46022 Valencia, Spain

e-mail: ivan.arribas@uv.es

J. E. Vila

e-mail: jose.e.vila@uv.es

I. Arribas

Ivie, C/Guardia Civil, 22 esc $21^{\circ}$, 46020 Valencia, Spain
} 


\section{Introduction}

Social capital has become a key issue in the literature of management and entrepreneurship. However, despite its frequent use in theoretical and empirical studies, there is a lack of consensus on an appropriate model for measuring this concept. For such reasons, the measurement of social capital has become a relevant research issue (as an illustration, the OECD and the World Bank launched an international working group to establish a set of key indicators of this capital, OECD 2002). The definition of a reliable and standard measure of social capital is not an easy task. First of all, there is not a consensus on the fact of social capital being a one-dimensional (Burt 1992) or a multidimensional (Koka and Prescott 2002) concept. Moreover, social capital can be defined at different levels and for distinct units of analysis: individuals (micro level), organizations (intermediate level) of the whole society (macro level).

This paper follows a micro level approach: it presents a measurement model of social capital of individuals. To analyze the empirical properties of the proposed model, it is applied and validated over a sample of Argentinean entrepreneurs. The aim of the paper is twofold. First of all, we participate in the open discussion on the nature of social capital and we show that the one-dimensional approach is not enough to capture the complex nature of social capital. Second, we present and validate a specific three-dimensional measurement tool that can be used to analyze the role of social capital in entrepreneurship research (for an example of such applications, see Fornoni et al. 2011). To achieve this double objective, an analysis of the related literature is presented in the section entitled 'The concept of social capital and its measurement'. The section entitled 'Hypotheses of the research' states our hypotheses on the nature of social capital and the dimension that constitutes this capital. Such hypotheses are empirically tested in the section entitled 'Results', according to the methodology described in 'Research methodology'. A section with 'Conclusions' closes the paper.

\section{The concept of social capital and its measurement}

Organizations deal with different sources of value: financial capital, such as cash, and bank deposits, investments and credit; human capital, including natural skills such as intelligence and other abilities acquired through education or professional experience; and social capital, referring to relations with colleagues, acquaintances or contacts which can provide opportunities to access financial and human resources (Burt 1992; Wu et al. 2009; Wagener et al. 2010; Tihula and Huovinen 2010). Roughly speaking, social capital refers to social relations among persons generating productive results (Szreter 2000; Smallbone et al. 2010; Ramírez et al. 2010). Social networks are valuable resources since they facilitate economic activity (Nahapiet and Ghoshal 1998; Burt 1992), allow entrepreneurs to be more efficient and access privileged business opportunities (Batjargal 2003; Abreu et al. 2010; Baregheh et al. 2009; Meliá et al. 2010; Rubalcaba et al. 2010; Toivonen and Tuominen 2009) and improve innovation (Shan et al. 1994; Powell et al. 1996; Ahuja 2000; Alpkan et al. 2010; Bonet et al. 2010; Romero-Martínez et al. 2010; Sundbo 2009; Un and Montoro-Sanchez 2010; Zhang and Duan 2010). 
In this paper we analyze social capital from an individual viewpoint: we focus on an entrepreneur's formal or informal links with other agents and the resources that she or he is able to access through these links. Burt (1992) relates the concepts of social capital and social network, and shows how the properties of an agent's position in a network might provide her or him with competitive advantages. With these considerations, Burt (1992), Lin et al. (1981) and Lin et al. (2010) approach the study of social capital not as a public but as a private good. The original contribution of Burt (1992) is that social capital can be managed like other types of capital: individual agents (entrepreneurs) are able to manage their social capital to obtain a 'return on investment' from it. In Burt's analysis, such management refers to an improvement in an agent's position in the network by locating her or himself in preferential points in the network, for instance by becoming the only connection between two isolated groups of agents. To optimize social capital management, the relevant analysis implies the characterization of these network topologies that may provide the agent with preferential locations generating competitive advantage. These ideas have been successfully applied in entrepreneurship literature (Smeltzer et al. 1991; Lin 2010; Comeche and Loras 2010) and other management fields. For instance, Brown and Butler (1995) analyze the impact of competitors' social networks on the performance of a company and show how the investment of time and resources in the creation and maintenance of such networks is directly associated with a growth in sales.

Measuring an entrepreneur's social capital is not an easy task. The literature on social capital presents an evolution of models to this end. Early measurement models were one-dimensional structural models, where an agent's social capital was just measured in terms of their relative position in their social network and the properties that such a position had within the global structure of the network. Some instances of these measurement models are presented in the studies by Nahapiet and Ghoshal (1998), based on the concept of structural holes, and Arribas and Vila (2010), based on preferential attachment network models. Koka and Prescott (2002) add a second dimension to measuring social capital, which goes beyond the structural one in the above papers. They introduce a new dimension, which is related to the characteristics of an agent's relations with other agents in the network, such us confidence or experience. This second dimension is called the relational dimension. Finally, Batjargal (2003) introduces a third dimension, the resources dimension, considering the sociological analysis in Lin (2001). Thus, the measurement model proposed by Batjargal (2003) integrates three dimensions of social capital: the first dimension depends on the structure of the network and the properties of the position occupied by the agent in the network (structural dimension), the second dimension summarizes the characteristics of the agent's relations, such as confidence, longevity of the link, etc. (relational dimension) and the third dimension measures the value of the resources that networked agents are able to provide (resources dimension).

These three dimensions of social capital are not directly observable and need to be measured indirectly through a series of observable indicators. Several such indicators have been proposed in the literature. For instance, (Nahapiet and Ghoshal 1998) suggest the following indicators for the structural dimension of social capital: number of links and other characteristics of the configuration of the network, such us density, hierarchy or connectivity level. To measure the relational dimension, Koka 
and Prescott (2002) suggest the following indicators: multiple links that represent the existence of different simultaneous relations between two given agents and repeated links representing the number of relations that two agents maintain over time. Both multiple and repeated links can be considered as measures of the confidence level between agents. An alternative trust indicator may be the duration of the relation (Gulati 1995). Finally, Koka and Prescott (2002) suggest the amount of resources available among an agent's acquaintances as indicator for the resource dimension, which is an indicator of quality in terms of power, experience, wealth, etc., of the agent's social environment, and mobility of resources or, in other words, the possibility of the actual use of these resources by the agent. These indicators are the departing point for establishing the items in our questionnaire, as presented in Table 1.

Table 1 Items in the questionnaire related to each dimension of social capital

\author{
Latent variables Items in the questionnaire \\ (name in the model)
}

Structural (STRUC) ST1. Do you consider yourself to be a person with a large number of contacts and acquaintances?

ST2. Just remember and mention the names or pseudonyms of the people you used to consult, ask advice from, ask a favor of or just to get their impression about your project. (Excl. partners)

ST3. Regarding the possibility of having better access to financing, did you have contacts or relationships that somehow provided access?

ST4. Regarding the possibility of having better market access, did you have contacts or relationships that somehow provided access?

ST5. Regarding the possibility of having better access to important information for project implementation, did you somehow have contacts or relationships that provided access?

ST6. Did you actually ask them for help?

ST7. Do you consider your main contact (i. e. your most relevant contact providing advice or support during the start-up) to be a person with a large number of contacts and acquaintances?

Resources (RESOUR) RS1. Regarding the possibility of access to finance, did you actually use relationships or contacts that somehow provided access?

RS2. Regarding the possibility of access to markets, did you actually use relationships or contacts that somehow provided access?

RS3. Regarding the possibility of access to important information for project implementation, did you actually use relationships or contacts that somehow provided access?

RS4. Your main contact, on what issues could she or he have helped? And finally, has she or he helped you?

Relational (RELATI) RL1. Would you share with your main contact any relevant or confidential information regarding your business project? And less critical information regarding your business idea?

RL2. Type of relationship with your main contact you had at that time (work/ professional, friendship, family, other)

RL3. How long had you known your main contact? (Years) 


\section{Hypotheses of the research}

An analysis of the literature on the measurement of social capital justifies the statement of the following hypothesis to be tested empirically:

Main Hypothesis (MH) Social capital has a multidimensional structure.

The nature of social capital can be considered as multidimensional only in the case of its different dimensions being independent. Such independence is suggested in many theoretical studies, such as Koka and Prescott (2002), who state that the value of social capital arises when an agent is linked to a diverse set of acquaintances that allows her or him to access diverse types of resources, independently of the total number and structural characteristics of these links. To test independence, we introduce three complementary hypotheses derived from $\mathrm{MH}$,

H1: Structural and relational dimensions of social capital are not correlated.

$\mathrm{H} 2$ : Relational and resource dimensions of social capital are not correlated.

H3: Structural and resource dimensions of social capital are not correlated.

\section{Research methodology}

The universe for this study is defined as those entrepreneurs who launched their business projects between 2000 and 2005 in the Republic of Argentina. We focus on start-ups in this period in order to analyze not only the role of social capital in the creation process but also during their consolidation or failure. This retrospective analysis is a must to meet the objectives of this study, even if it might generate some distortions in the information provided by the entrepreneurs due to memory failures or post-hoc rationalization of past events.

The sample frame was established as a combination of two databases: the Observatory of SMEs, developed by Sepyme (Secretaría de la pequeña y mediana empresa - secretary of SMEs) in cooperation with universities in the province of Buenos Aires, and the general SME database of Sepyme. Both databases provide periodical information on SME creation. From this frame, a stratified sample of 300 start-ups was selected. Stratification was designed according to two variables: location of the company (province) and activity sector (aggregated as industrial or service entrepreneurial projects). For each sample unit, four alternative substitutive companies were chosen. Fieldwork was performed from April to July 2008, with face-to-face interviews in the province of Buenos Aires and telephone interviews in the other provinces. The number of valid questionnaires finally collected was 282 . Such a sample size does not allow for empirical analysis at provincial or at activity sector levels, but constitutes appropriate material to provide representative results at an aggregate Republic of Argentina level. Specifically, the maximum sample error when estimating the proportion of each possible answer to a dichotomy variable in the worst situation $(\mathrm{p}=\mathrm{q}=50 \%)$ is $5.8 \%$, assuming a confidence level of $95 \%$.

The research hypotheses stated above have been tested by using the measurement sub-model of the Structural Equations Models (SEM). These models allow for the 
measurement of latent variables (variables that cannot be measured directly) through a set of measurable variables or indicators. SEM models also allow for estimation among such latent variables. Specifically, we use the LISREL (LInear Structural RELations) model introduced by Jöreskog (1973) and its associated estimation techniques.

\section{Results}

Multidimensional measurement model for social capital

In this section we present and analyze the SEM used to test the main hypotheses and their corresponding sub-hypotheses. To this end, we consider a measurement SEM sub-model with three latent variables corresponding to the three dimensions of social capital in our model: structural, resources and relational. To complete the model description, we need to specify the observed variables that define each latent variable. Table 1 presents the items in the questionnaire that are related to each dimension and that will be the base to construct the variables to be used in the measurement of each dimension of social capital:

The final set of observable variables to be used has been obtained after specification, estimation and validation of a series of alternative SEM measurement sub-models. Such observable variables have been selected following two considerations: their theoretical importance and their practical capacity to measure the three latent variables.

In our model, the structural dimension (latent variable STRUCT) is measured through three observable variables:

- RELLEV or self-perception of the level of contacts and acquaintances, obtained from item ST1.

- CONSUL or number of persons whom the entrepreneur asked for advice or support during the launching of her or his project, obtained from items ST2 to ST6.

- CONECT or perception of the level of contacts and acquaintances of her or his main contact, obtained from item ST7.

Resource dimension (latent variable RESOUR) is measured through the following two observable variables:

- RESLEV or level of resources actually obtained from the contacts in entrepreneur's social network, obtained from items RS1 to RS3.

- CONUSE or utilization of resources provided by the entrepreneur's main contact, obtained from item RS4.

Finally, the relational dimension (latent variable RELATI) is measured through these three observable variables:

- CONFID or confidence level with the main contact, obtained from items RL1.

- PERSON (binary variable). This variable equals 1 if the relation with the main contact is not only professional, but also has a family or friendship nature. This information is obtained from item RL2.

- TIME or number of years that the entrepreneur had known her or his main contact, obtained from item RL3. 
All these variables and their relationships are presented in Fig. 1, which summarizes the specification of the SEM measurement sub-model to be used to test the research hypotheses.

The model in Fig. 1 is estimated in two stages: a first TSLS estimation provides the values to be used as initial values for the second maximum likelihood estimation. According to previous notation, the estimated model is given by

$$
\begin{aligned}
& \text { RELLEV }=\underset{(N A)}{1.00 S T R U C}+\widehat{\delta}_{1} \\
& \text { CONSUL }=\underset{(2.51)}{0.23} \text { STRUC }+\widehat{\delta}_{2} \\
& \text { CONECT }=\underset{(5.53)}{0.71} \text { STRUC }+\widehat{\delta}_{3} \\
& \text { RESLEV }=\underset{(\text { NA })}{1.00 R E S O U R}+\widehat{\delta}_{4} \\
& \text { CONUSE }=\underset{(2.45)}{0.24} \text { RESOUR }+\widehat{\delta}_{5} \\
& \text { CONFID }=\underset{(N A)}{1.00} \text { RELATI }+\widehat{\delta}_{6} \\
& \text { PERSON }=\underset{(2.47)}{7.04} \text { RELATI }+\widehat{\delta}_{7} \\
& \text { TIME }=\underset{(3.03)}{5.22} \text { RELATI }+\widehat{\delta}_{8}
\end{aligned}
$$

Fig. 1 Specification of the measurement model for social capital

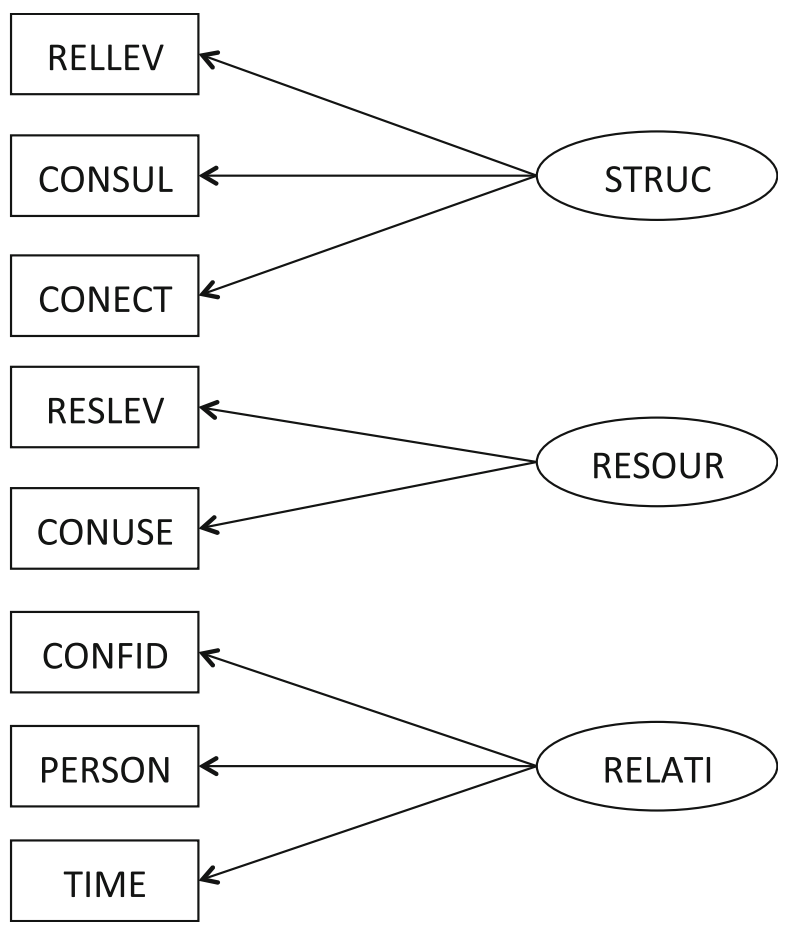


where, in parentheses and below each coefficient, the value of the $t$-statistic associated with the significance contrast of the coefficient is shown. This statistic asymptotically follows a Student's $t$ distribution with 17 degrees of freedom. ${ }^{1}$ From the $t$-values associated with the coefficients, there is no empirical evidence to accept the statistical hypotheses of nullity of any of the coefficients in the measurement model. Additionally, the signs of all the coefficients are positive and all the observable variables exhibit a direct relation with the latent variables they are measuring. The values of the goodness-of-fit statistics (Chi-square statistic, goodness-of-fit index, and root square mean error) shown in Table 2 confirm the validity of the model.

The estimated model has some relevant implications for the discussion on the measurement of social capital. First, the structure and resource dimensions can be measured by considering the following indicators:

- Subjective indicators of the entrepreneur's self-perception on her or his own level of connectivity and capacity to obtain resources through their social network (variables RELLEV and RESLEV)

- Subjective indicators of the entrepreneur's perception on the level of connectivity and resources of her or his main contact (variables CONECT and CONUSE)

- An objective indicator, consisting of the total number of persons whom the entrepreneur has asked for advice or support in the launching of their company (variable CONSUL).

Notice that all these indicators consider only local information on how the entrepreneur is linked to their direct contacts, and certain characteristics of their main contact. However, they do not refer to any global property of the social network as a whole. Additionally, the quality of the connection is strongly related to the origin and nature of the link itself: links proceeding from a family or friendship environment generate a higher level of the relation dimension of social capital than those proceeding from a purely professional framework.

Independence between the dimensions of social capital

To test hypotheses $\mathrm{H} 1, \mathrm{H} 2$ and $\mathrm{H} 3$, which raise the lack of correlation between the three dimensions of social capital, it is necessary to estimate the matrix $\Phi$ in the LISREL model (Jöreskog 1973), which includes the mutual correlations between the latent variables and the $t$-statistic contrast for each correlation coefficient. The estimated matrix obtained from our sample is:

$$
\widehat{\Phi}=\left(\begin{array}{ccc}
1 & 0.46 & -0.01 \\
& (7.08) & (-0.32) \\
& 1 & 0.05 \\
& & (1.90) \\
& & 1
\end{array}\right)
$$

where the ij element of the matrix represents the correlation between latent variables ith and jth. Below each coefficient and in brackets is shown the $t$-statistic associated

\footnotetext{
${ }^{1}$ For each latent variable, the coefficient of an observable variable needs to be set to 1 to define the measurement scale. $t$ statistics are not avaiable (NA) for these fixed coefficients.
} 
Table 2 Goodness-of-fit statistics for the multidimensional model

\begin{tabular}{lc} 
Chi-square statistic: & \\
Value & 249.53 \\
Degrees of freedom & 17 \\
$P$-value & 0.0000 \\
Goodness-of-fit index & 0.91 \\
Root square mean error & 0.10 \\
\hline
\end{tabular}

with the contrast of nullity of the coefficient, which is asymptotically distributed as a $t$-Student with 17 degrees of freedom. The results are shown in Fig. 2:

Thus, there is no empirical evidence to reject the null hypothesis that the latent variable RELATI is uncorrelated with the other two. Therefore, it is possible to accept hypotheses $\mathrm{H} 1$ and $\mathrm{H} 2$. This result supports the theoretical approach suggested by Burt (1992), Koka and Prescott (2002), Tsai and Ghoshal (1998) and Gulati et al. (2000), who suggest that networks with little structure, such as low density, are able to provide entrepreneurs with diverse contacts that allow them to access a variety of resources. However, this empirical evidence contrasts with some aspects of the work by Coleman (1988), who argues that social capital arises from dense social interactions between agents that form a network.

We reject the null hypothesis of lack of correlation between the structural and resource dimensions, and consequently hypothesis $\mathrm{H} 3$. Note that even when we reject that the coefficient is zero, its estimated value is not very high (less than 0.50 ). This justifies the multidimensional approach which goes beyond a one-dimensional assessment of social capital, in line with research by Burt (1997), Nahapiet and Ghoshal (1998) or Koka and Prescott (2002).

We therefore justified that the three dimensions cannot be reduced to a single dimension without losing information that is relevant. This supports the $\mathrm{MH}$, which is formally proven below.

Multidimensional vs. one-dimensional model for social capital

The discussion about the appropriateness of using a multidimensional definition of social capital compared to the one-dimensional definition is of great conceptual interest. A multidimensional model is less parsimonious than an alternative onedimensional model, where all the observable variables are considered as indicators of a single concept (called social capital). In this subsection, we compare the

Fig. 2 The dimensions of social capital and estimated correlations between them
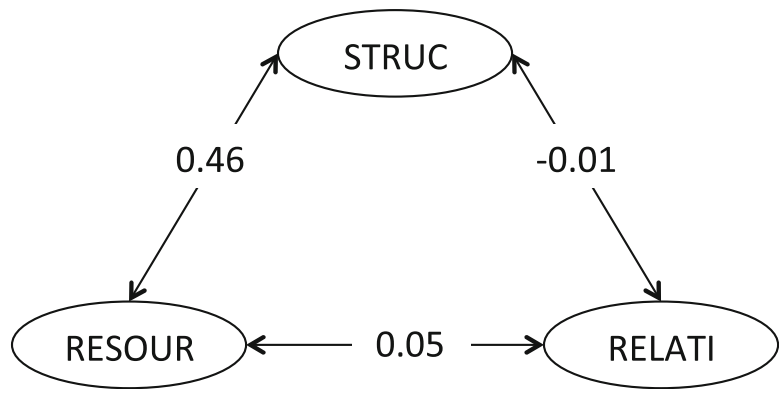
tridimensional and one-dimensional models to show that the former is more appropriate than the latter, since it exhibits a higher level of accuracy.

Let us now consider only one latent variable, SOCCAP (social capital), which can be measured by the eight observable variables considered in the multidimensional model (Fig. 3).

The estimation of the one-dimensional SEM is given by:

$$
\begin{aligned}
& \text { RELLEV }=\underset{(N A)}{1.00 S O C C A P}+\widehat{\delta}_{1} \\
& \text { CONSUL }=\underset{(0.34)}{0.13 S O C C A P}+\widehat{\delta}_{2} \\
& \text { CONECT }=\underset{(4.05)}{0.50 S O C C A P}+\widehat{\delta}_{3} \\
& \text { RESLEV }=\underset{(6.69)}{1.20} \text { SOCCAP }+\widehat{\delta}_{4} \\
& \text { CONUSE }=\underset{(2.20)}{0.12} \text { SOCCAP }+\widehat{\delta}_{5} \\
& \text { CONFID }=\underset{(5.13)}{0.66 S O C C A P}+\widehat{\delta}_{6} \\
& \text { PERSON }=\underset{(5.50)}{0.72 S O C C A P}+\widehat{\delta}_{7} \\
& \text { TIME }=\underset{(3.95)}{0.48 S O C C A P}+\widehat{\delta}_{8}
\end{aligned}
$$

Fig. 3 One-dimensional model specification for the measurement of social capital

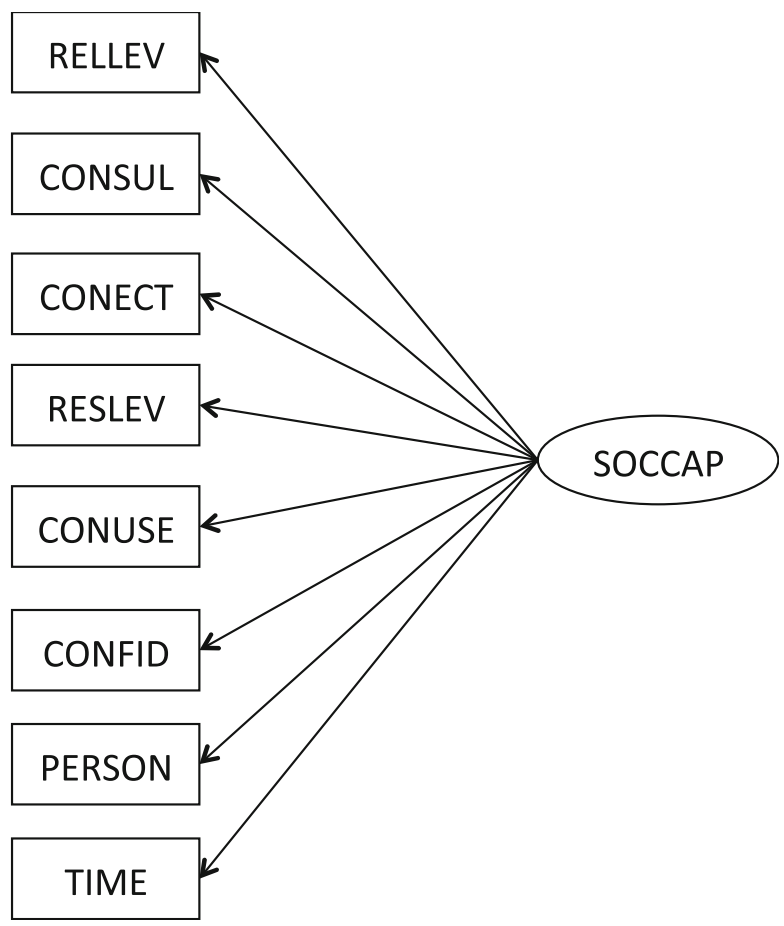


The goodness-of-fit statistics shown in Table 3 tell us that the one-dimensional model has explanatory power $(p$-value $=0.000)$. Furthermore, the square errors are small and the goodness-of-fit index is adequate, although lower than that of the multidimensional model. The specific values of the statistics can be seen in Table 3 .

In our analysis, empirical evidence suggests that the multidimensional approach is more suitable. Thus the goodness-of-fit measure, as presented in Table 2, is worse if we consider all the observable variables as a measurement of a single latent variable (in this case, the goodness-of-fit index is reduced to 0.79 from the 0.91 of the multidimensional model). To contrast the null hypothesis that the one-dimensional model has an explanatory capacity similar to the multidimensional, we have used the chi-square statistic:

$$
\chi^{2}=\chi_{\mathrm{o}}^{2}-\chi_{\mathrm{m}}^{2}=120.56
$$

where $\chi_{\mathrm{o}}^{2}$ corresponds to the one-dimensional model for measuring social capital and $\chi_{\mathrm{m}}^{2}$ with the model that considers the three distinct dimensions. Since under the null hypothesis this statistic follows a chi-square distribution with 15 degrees of freedom (the difference between the degrees of freedom of both models), the associated $p$-value is 0.000 and it should be accepted that the explanatory power of the multidimensional model is significantly higher than that of the one-dimensional model. This leads us to accept the $\mathrm{MH}$ and consider the multidimensional nature of social capital.

Furthermore, there is enough empirical evidence to reject the hypothesis that the latent variable RELATI correlates with the other two (H1 and $\mathrm{H} 2$ ). The only nonzero correlation, between the structural dimensions and resources one, is not too high (less than 0.50 ), so we can assume that the three dimensions have a very low level of correlation, albeit not zero.

\section{Conclusions}

The literature reviewed has led us to raise a number of issues related to the onedimensional or multidimensional nature of social capital and the consequences of this on the development of a measurement model for social capital.

From our empirical analysis we conclude that it is more appropriate to address the measurement of social capital from a vector point of view that takes into account that social capital is composed of three independent dimensions. Specifically, a first dimension encompasses the structural features of the network (structural dimension), a second dimension explores the characteristics of these relationships, such as

Table 3 Goodness-of-fit statistics for the one-dimensional model

$\begin{array}{lc}\text { Chi-square statistic: } & \\ \text { Value } & 370.09 \\ \text { Degrees of freedom } & 2 \\ P \text {-value } & 0.0000 \\ \text { Goodness-of-fit index } & 0.79 \\ \text { Root square mean error } & 0.12\end{array}$


confidence and experience gained over time (relational dimension) and finally a dimension that provides the resources embedded in a network that can be mobilized or materialized through the same (resource dimension).

In particular, a comparison between the one-dimensional model and the multidimensional one of the measurement of social capital allows us to reject the null hypothesis that the one-dimensional model has a capacity of adjustment similar to the multidimensional. Therefore, in accordance with $\mathrm{MH}$, the multidimensional approach that considers social capital to consist of three independent dimensions, structural, relational and resources, is more appropriate.

The measurement model presented in this paper can be used in further research on the role of social capital in the performance of entrepreneurial projects and the impact of alternative strategies of social capital management on the survival and development of new businesses (see for instance Fornoni et al. 2011).

Acknowledgement Iván Arribas and José Vila thank both the Spanish Ministry of Science and Technology, and European Feder Funds for financial support under projects SEJ2007-66581 and ECO2010-20584.

\section{References}

Abreu, M., Grinevich, V., Kitson, M., \& Savona, M. (2010). Policies to enhance the 'hidden innovation' in services: evidence and lessons from the UK. Service Industries Journal, 30(1), 99-118.

Ahuja, G. (2000). Collaboration networks, structural holes, and innovation: a longitudinal study. Administrative Science Quarterly, 45, 425-457.

Alpkan, L., Bulut, C., Gunday, G., Ulusoy, G., \& Kilic, K. (2010). Organizational support for intrepreneurship and its interaction with human capital to enhance innovative performance. Management Decision, 48(5), 732-755.

Arribas, I., \& Vila, J. E. (2010). Guanxi management in Chinese entrepreneurs: a network approach. Working paper 8, BBVA Foundation, Bilbao, Spain.

Baregheh, A., Rowley, J., \& Sambrook, S. (2009). Towards a multidisciplinary definition of innovation. Management Decision, 47(8), 1323-1339.

Batjargal, B. (2003). Social capital and entrepreneurial performance in Russia: a longitudinal study. Organization Studies, 24, 535-556.

Bonet, F. J. P., Peris-Ortiz, M., \& Gil-Pechuan, I. (2010). Integrating transaction cost economics and the resource-based view in services and innovation. Service Industries Journal, 30(5), 701-712.

Brown, B., \& Butler, J. (1995). Competitors as allies: a study of entrepreneurial networks in the U.S wine industry. Journal of Small Business Management, 33, 57-66.

Burt, R. (1992). Structural holes: The social structure of competition. Cambridge: Harvard University Press.

Burt, R. (1997). The contingent value of social capital. Administrative Science Quaterly, 42, 339-365.

Coleman, J. (1988). Social capital in the creation of human capital. American Journal of Sociology, 94, 95-120.

Comeche, J. M., \& Loras, J. (2010). The influence of variables of attitude on collective Entrepreneurship. International Entrepreneurship and Management Journal, 6(1), 23-38.

Fornoni, M., Arribas, I., \& Vila, J. E. (2011). An entrepreneur's social capital and performance: the role of access to information in the Argentinean case. Journal of Change Management, forthcoming.

Gulati, R. (1995). Social structure and alliance formation patterns: a longitudinal analysis. Administrative Science Quaterly, 40, 619-652.

Gulati, R., Nohria, N., \& Zaheer, A. (2000). Strategic networks. Strategic Management Journal, 21, 203215.

Jöreskog, K. (1973). A general method for estimating a linear structural equiation system. In A. S. Goldberger \& O. D. Duncan (Eds.), Structural equation models in the social sciences. New York: Academic. 
Koka, B., \& Prescott, J. (2002). Strategic alliances as social capital: a multidimensional view. Strategic Management Journal, 23, 795-816.

Lin, N. (2001). Building a network theory of social capital. In N. Lin, R. Cook, \& S. Burt (Eds.), Social capital: Theory and research. New York: Aldine de Gruyter.

Lin, C. H. (2010). In search of e-service value: technology-exploitation vs. certainty-seeking online behaviours. Service Industries Journal, 30(8), 1377-1400.

Lin, N., Ensel, W., \& Vaughn, J. (1981). Social resources and strength of ties: structural factors in occupational status attainment. American Sociological Review, 46, 393-405.

Lin, E., Lin, T. M. Y., \& Lin, B. W. (2010). New high-tech venturing as process of resource accumulation. Management Decision, 48(8), 1230-1246.

Meliá, M. R., Pérez, A. B., \& Dobón, S. R. (2010). The influence of innovation orientation on the internationalisation of SMEs in the service sector. Service Industries Journal, 30(5), 777-791.

Nahapiet, J., \& Ghoshal, S. (1998). Social capital, intellectual capital and the organizational advantage. Academy of Management Review, 23, 242-266.

OECD (2002). Social capital: The challenge of international measurement. London: Conference OCDE/ ONS, (http://www.oecd.org/)

Powell, W., Koput, K., \& Smith-Doerr, L. (1996). Interorganizational collaboration and the locus of innovation: networks of learning in biotechnology. Administrative Science Quarterly, 41, 116-146.

Ramírez, A. R., Orejuela, A. R., \& Vargas, G. M. (2010). New perspectives for the managerial entrepreneurship. International Entrepreneurship and Management Journal, 6(2), 203-219.

Romero-Martínez, A. M., Ortiz-de-Urbina-Criado, M., \& Soriano, D. R. (2010). Evaluating European Union support for innovation in Spanish small and medium enterprises. Service Industries Journal, 30 (5), 671-683.

Rubalcaba, L., Gallego, J., \& Hertog, P. D. (2010). The case of market and system failures in services innovation. Service Industries Journal, 30(4), 549-566.

Shan, W., Walter, G., \& Kogut, B. (1994). Interfirm cooperation and startup innovation in the biotechnology industry. Strategic Management Journal, 15, 387-394.

Smallbone, D., Welter, F., Vytovich, A., \& Egorov, I. (2010). Government and entrepreneurship in transition economies: the case of small firms in business services in Ukraine. Service Industries Journal, 30(5), 655-670.

Smeltzer, L., Van Hook, B., \& Hutt, R. (1991). Analysis of the use of advisors as information sources in venture startups. Journal of Small Business Management, 29, 10-16.

Sundbo, J. (2009). Innovation in the experience economy: a taxonomy of innovation organisations. Service Industries Journal, 29(4), 431-455.

Szreter, S. (2000). Social capital, the economy, and education in historical perspective. Social capital: Critical perspectives. Oxford: Oxford University Press.

Tihula, S., \& Huovinen, J. (2010). Incidence of teams in the firms owned by serial, portfolio and first-time entrepreneur. International Entrepreneurship and Management Journal, 6(3), 249-260.

Toivonen, M., \& Tuominen, T. (2009). Emergence of innovations in services. Service Industries Journal, 29(7), 887-902.

Tsai, W., \& Ghoshal, S. (1998). Social capital and value creation: The role of intrafirm networks. Academy of Management Journal, 41, 464-476.

Un, C. A., \& Montoro-Sanchez, A. (2010). Public funding for product, process and organisational innovation in service industries. Service Industries Journal, 30(1), 133-147.

Wagener, S., Gorgievski, M., \& Rijsdijk, S. (2010). Businessman or host? Individual differences between entrepreneurs and small business owners in the hospitality industry. Service Industries Journal, 30(9), $1513-1527$.

Wu, L. Y., Wang, C. J., Tseng, C. Y., \& Wu, M. C. (2009). Founding team and start-up competitive advantage. Management Decision, 47(2), 345-358.

Zhang, J., \& Duan, Y. (2010). The impact of different types of market orientation on product innovation performance: Evidence from Chinese manufacturers. Management Decision, 48(6), 849-867. 